PART 1

Transnational African Perspectives 


\title{
Addressing Learners' Individual Needs with Turnitin
}

\author{
Eva Sujee
}

\section{1 \\ Introduction}

Learners have more access to Web-based, electronic, and multimedia communication devices than ever before while also being able to connect very easily for access to information, communities or resources. The global expansion of technology has resulted in schools becoming increasingly diverse, and teachers need to provide multicultural, inclusive and multilingual contexts. New cultural practices are being formed and the interaction of multiple texts or voices is inevitable (Danzak, 2011). Greene, Yu, and Copeland (2014) confirm that it is vital to acquire the skills required to use internet technology for 21st century learning, with the internet playing a prominent role in both home and classroom. In addition, Carneiro and Gordon (2013) suggest that teachers need to provide the necessary flexible learning environments to support scaffolding.

Bruett (2006) is of the opinion that there is still a profound gap between the skills that learners acquire at school and the skills required in the workplace. It is essential that education becomes rigorous and meaningful if it is to produce learners with the competencies that are relevant to the 21st century workforce (Bruett, 2006). In this regard, Nelson, Christopher, and Mims (2009) propose that Web 2.o technologies may provide opportunities for collaborative learning and knowledge building. Online environments provide platforms for learners from diverse backgrounds to come together and engage in collaborative learning. The integration of Web 2.o technologies by skilful teachers may result in the acquisition of the 21st century skills that are necessary to learners in view of the global economy and industry. Web 2.o technologies may provide opportunities to learners to engage in active learning, to take responsibility for their own learning and develop high-order thinking and creative skills. Cramer (2007) and Nelson (2008) emphasise that more needs to be done to help learners to take responsibility for their learning. In addition, Zhang (2010), Golonka et al. (2014) and Holland and Holland (2014) indicate the need for further studies on the effect of specific technologies on learners with different proficiency levels in a diverse learning class. This chapter elaborates on the acquisition or learning 
of a First Additional Language (FAL), using the collaborative online discussion board and the Grade Mark feature on Turnitin, a plagiarism detection tool, to address leaners' individual needs, placing written corrective feedback (WCF) at the centre of the learning experience. The e-assessment tool of Turnitin was used to provide individual feedback in order to address the individual needs of the learners in the multilinguistic language class.

2

\section{National Context}

South Africa's history of language policy and practice in education has been influenced by ideological and political interests instead of pedagogical considerations. Since the 19th century black South Africans have converted English into the language of aspiration, national unity and liberation (Alexander, 2005). Manyike and Lemmer (2014) confirm this fact when they assert that English has become central in post-apartheid South Africa and it has become the preferred medium of instruction in higher education, commerce and government (referred to in post-1994 policy documents as the language of learning and teaching [LoLT] in public schools). Nevertheless, equity education in the country is not achieving the desired results because of the fact that black learners are learning English as an additional language, but they are expected to master all the other learning areas using English as a medium. Annual reports such as the national school-leaving examinations, literacy and numeracy assessments and international benchmarking assessments all reveal the underachievement of black learners in South Africa (Manyike \& Lemmer, 2014).

Manyike and Lemmer (2014) indicate that during the apartheid era (19481994), a policy of bilingualism was in place. This policy accorded status only to English and Afrikaans as official languages. Thus, the needs of African speakers were ignored and the policy accommodated white English and Afrikaans speakers only. The medium of instruction in black schools was highly politicised. Although the medium of instruction in the first four years of schooling was in the learners' home language, English and Afrikaans were taught as subjects from the first year of schooling, thus forcing children to be trilingual. By the 1970s English and Afrikaans were used on a 50/5o basis as a medium of instruction while the home language was used for non-examination subjects only. This lowered the status of the home language and demeaned its usefulness. This situation led to the Soweto riots in 1976.

After 1994 the new government went to great lengths to shape the Language in Education Policy (LiEP) (Department of Education, 1997). The Constitution of the Republic of South Africa (South Africa, 1996) gave equal status to all 11 South African languages (English, Afrikaans, Sepedi, Setswana, Sesotho, 
Tshivenda, Siswati, isiNdebele, isiXhosa, Xitsonga, and isiZulu). The South African Schools Act (Republic of South Africa, 1996) empowered school governing bodies to decide on the language policy while the LiEP (Department of Education, 1997) promoted bilingualism by allowing the home language as a medium of instruction in early primary schooling, followed by the introduction of additional languages. The Revised National Curriculum Statement (Department of Education, 2002b) stipulates that all learners have to study their home language as well as at least one additional language as language subjects from Grade 1. The Curriculum and Assessment Policy Statements (CAPS) (Department of Basic Education, 2012) reaffirmed this stipulation. It is, thus, the right of all South African learners to be educated in the official language(s) of their choice. Nevertheless, this must be in the context of what is realistically practicable (Coffey \& Atkinson, 1996).

In addition, a new linguistically-diverse environment has been created by the desegregation of formerly whites-only schools, and innovative ways of teaching are necessary to accommodate multilingualism in schools. South Africa has the most progressive language in education policies which address the issue of multilingualism (Department of Basic Education, 2013).

At the time of the study the researcher was a high school teacher at a private school for girls. In 2005 , the school management decided to integrate technology into the school curriculum in order to prepare learners for the digital environment both in tertiary institutions and the corporate world. The initiative commenced by supplying all the teachers with laptops and providing them with training. Subsequently, a learning technologies facilitator was appointed to help the teachers with the smart boards and education software and with the smooth integration of technology into their lessons.

All the learners have to achieve the same skills at the end of their Grade 12 year irrespective of their different levels of Afrikaans proficiency or their exposure to Afrikaans. Learners have to achieve at least $50 \%$ in a first additional language in Grade 12 for university entrance. The learners and the teachers at the school are fortunate to be surrounded with technology. The researcher wanted to explore the effect of technology on learning in a multilingual language class to address the individual needs of the learners. The study focuses on one class of girl learners, from different backgrounds and different cultures and with Afrikaans as home language, first additional language, second additional language or even third additional language. The learners had not necessarily received tuition in Afrikaans as home language in pre-primary, primary or high school. They also did not, as is expected in the curriculum, have a solid foundation of Afrikaans FAL. They differ in respect of culture, race and the social circles in which they move and interact. The teacher was faced with a diverse class with different levels of Afrikaans proficiency which he or she needs to accommodate. 
Learners have a choice between Afrikaans and Sepedi as a first additional language at the school. If foreign learners start Grade 8 in South Africa they are accorded immigrant status and are not compelled to do a first additional language to obtain their National Senior Certificate. However, one of the complicating factors is that a vast majority of the learners are not South Africans, with many coming from Botswana and choosing to do Afrikaans as a first additional language. There are also learners who have forgotten how to speak Afrikaans as a result of their having spent part of their high school careers overseas. As a result, there are many cases of learners taking Afrikaans for the first time as a subject in their Grade 8 year. They do not have the required vocabulary or foundation for the level of Afrikaans proficiency required in that grade and this proves frustrating for all parties concerned: learners, parents and teachers. Teachers do not have either the time or the professional qualification to start with the foundation curriculum in order to teach a learner Grade 2 Afrikaans: how to read and write Afrikaans. There is also another factor which must be taken into account, namely, that there are Afrikaans-speaking learners who speak Afrikaans fluently as well as those learners who are fully bilingual because of the social circles in which they move. They do not enjoy the Afrikaans class because it does not challenge them sufficiently. In addition, these Afrikaans-speaking learners are often extremely gifted and this exacerbates their boredom and they face no real challenges in class. In other words, the teacher is faced with a diverse class with different levels of Afrikaans proficiency which he or she needs to accommodate. Therefore, this research addresses the following primary research question: How can Turnitin be utilised to address every learner's individual learning need?

\section{Purpose of the Study}

The purpose of this study was to explore the effect of information computer technology (ICT) on First Additional Language (FAL) learning in a multilinguistic class. This study also investigates how Turnitin can be used to address the individual needs of learners.

There are four main objectives to the literature review which was conducted for the purposes of this research study: firstly, to examine the way in which traditional literacy has evolved into new literacies in the classrooms today; 
secondly, to investigate how a first additional language is mastered; thirdly, to explore how computer technology (ICT) influences language learning in order to establish a theoretical sensitivity; and lastly, to look at previous studies conducted on Turnitin and written corrective feedback (WCF).

\subsection{New Literacies}

Traditional literacy may no longer be enough for survival in this digital era because of the emerging technologies of the 21st century. Literary practices are changing because of the broad social, economic and technological changes in our everyday life, education, the media as well as the workplace. Accordingly, we need an expanded literacy to account for a culturally and linguistically diverse context and a society that is increasingly becoming more globalised. With globalisation, an increasing number of interrelated multifarious cultures and plurality of texts are emerging. More text forms such as visual images are appearing because of information and multimedia technologies, and it is essential that people fully understand and competently engage with these multimodal texts. People need to equip themselves with these new literacies if they are to engage in meaningful communication in this new digital environment. Language and print literacy are no longer sufficient for the multimodal content that is utilised in order to communicate (Cope \& Kalantzis, 200o). Literacy is a crucial skill for economic prosperity, and even small improvements in national literacy levels may have a huge impact on the socio-economy (Carneiro \& Gordon, 2013). In the global competitive environment digital technologies provide instant access to a large number of resources in order to solve problems effectively in a short time. Carneiro and Gordon (2013) are of the opinion that literacy today requires life-wide or lifelong learning individuals who are able to survive in an environment that is characterised by fast-moving technological innovations.

We need to be lifelong learning individuals for effective engagement on social media. The increased technological environment has brought about huge changes in the socialising aspect of society with the creation of social media. Learners are engaging more and more in written communication instead of oral communication as a result of social media and are constantly busy conveying messages, feelings and emotions via social media. Thus, the digital learners are using texts as their primary method of communication. Teachers and researchers are also eager to investigate the learning that takes place in online social settings. Mere access to social media is not enough and new media literacies are needed to engage fully in online settings. There is, thus, a gap between those who know how to engage fully in social media and those who do not. Therefore, it is vital for teachers to understand the literacies which are necessary for effective engagement in online settings. 
These new literacies are referred to as "new media literacies", "new literacies" or "digital literacies" (Kimmons, 2014). This confirms the notion of Carneiro and Gordon (2013) that new literacies are as essential as a driving licence in this high-tech, 21st-century society. Huffaker (2005) refers to this digital literate skill as being digitally fluent. It refers to how comfortable an individual is with the use of computers. New literacies need to be considered in terms of the use of technology because the emergence of new technologies has changed the nature of literacy (Tapscott, 1998). Learners require the ability to read, comprehend and interact with technology in order to survive in the new media ecology (Coiro, 2003). In other words, literacy has evolved to include several new literacies such as visual, financial, health, social, digital, mathematics, functional and media literacies. According to a review conducted by Cervi, Paredes, and Tornero (2010), literacy has evolved from reading and writing to electronic media to digital media and to a more comprehensive literacy that refers to both the internet and Web. 2.o. Hobbs, Felini, and Cappello (2011) use the term "expanded literacy" in the new literacies to describe the focus that has shifted from the alphabetic and written texts to a literacy that encompasses social communication and ideology.

Chen, $\mathrm{Wu}$, and Wang (2011) argue that it is vital that individuals become new media "literate" in this new high tech, 21st century society. The authors also highlight the fact that most researchers see the new media literacy as multiliteracies (Carstens, 2012). The term "multiliteracies" was coined by the New London Group and focuses on the multiple communication channels that have arisen as a result of the increased linguistic and cultural diversity which in turn has come about because of the digital technology world in which we live (Cope \& Kalantzis, 2000). Zammit (2011) agrees that we need to be multiliterate to be able to function fully in the digital society. In addition, Jewitt (2008, p. 245) notes that the pedagogic aim of multiliteracies is to expose the learners to opportunities to engage with the wide range of literacy practices as well as the multiple and multimodal texts with which they are confronted on a daily basis. Multiliteracies promote individualised learning because they recognise the multiple ways in which learners make meaning. Furthermore, they encourage pedagogies that afford equal opportunities to both traditional and non-traditional learners to learn in ways that enable them to participate fully in private, community, public and economic life (Newfield \& Maungedzo, 2006). Being "multiliterate" also implies the ability to handle the social meanings and, consequently, the identities that each social setting evokes, the capacity to make meaning for different audiences, the ability to move between discourses and across genres and to apply the appropriate linguistic practice to each setting (Devereux \& Wilson, 2008). 


\subsection{First Additional Language (FAL)}

Learners use their home language which they have already mastered when they first enter school. In Grades 2 and 3 understanding and speaking languagebasic interpersonal communication skills are developed (Department of Basic Education, 2012).

The four skills in language include listening, speaking, reading and writing. There is greater focus on these skills in the intermediate and senior phases than in the previous phases. In addition, there is more exposure to the First Additional Language with learners using the language for reading and thinking. They read more and develop their academic cognitive skills. They also use their aesthetic and imaginative abilities in the additional language. It is expected that learners should be reasonably proficient in the First Additional Language by Grade 10. Unfortunately, however, this is not always the case and teachers are being challenged to help learners to meet the required standards in Grade 12 (Department of Basic Education, 2012).

According to the National Curriculum Statement Grade R-12 (Department of Basic Education, 2012), the specific aims in a first additional language include the following: learners must be able to communicate accurately and appropriately; use the additional language for academic learning across the curriculum; listen, speak, write and present with confidence and enjoyment; think independently and analytically; be able to express their experiences and findings orally and in writing; use the additional language to access and manage information across the curriculum; and become critical and creative thinkers.

The National Curriculum Statement Grade R-12 (Department of Basic Education, 2012) also departs from the traditional approach that learners must first master the basic skills in their home language before they start reading in an additional language. It is expected of teachers to start second-language reading in the middle of Grade 1. Teachers have to clarify the differences between the phonics and sentence structures of the second language and the learners' home language. However, the reality is that the languages are very different and the learners do not have the basics of these languages in place. In addition, the different language areas have different levels of language skills. The benefit of starting with an additional language as early as in Grade 1 is the extent of vocabulary that learners acquire. According to Owen-Smith (2012), studies have shown that the earlier a learner is exposed to an additional language, the better.

\subsection{Technology Integration}

The issue in teaching and learning is no longer whether or not teachers should integrate technology into their teaching but, rather, how they should use 
technology in their teaching in order to provide new opportunities for learning (Angeli \& Valanides, 2009). Mishra and Koehler (2008) maintain that there is no one ideal way in which to integrate technology into the curriculum and, in fact, the integration of technology must be creatively designed for a specific subject matter within a specific classroom context. Gordon et al. (2009) reported that the "ideal" learning environment for key competencies should encompass a more individualised approach compared to the traditional whole class approach, collaborative cross-curricular teaching as well as sound leadership that builds on the vision of school development and encourages teamwork.

Barr and Gillespie (2003, p. 69) regard learning with technology as an integrated process, stating that

... a computer-based environment needs to be carefully constructed in order to ensure that all the other components of learning are effectively integrated into it. It is important to ensure that the uses of computer technology in this type of environment are not seen as separate, but rather that they are integrated, working together to enhance the process of teaching and learning ... CALL packages must not be seen as standalone creations.

Thus, technology is a teaching tool and it must be used to integrate the learning and teaching methods with the available resources. In addition, technology must be used to realise pedagogical goals and it must not be forced to fit a lesson. If other more conventional teaching and learning methods may be used to ensure that the learners grasp the subject matter successfully then there is little point in using computer technology. Technology is not a standalone tool but, instead, it offers support to the total environment of learning. It is also extremely important that the principles of sound pedagogy are understood because technology is changing constantly and at a rapid pace (Murray \& Barnes, 1998). The pedagogical goals must be clear and sound teaching methods must be regarded as paramount. The use of technology merely supports the realisation of the pedagogical goals and, thus, these goals must be considered before technology may be integrated into teaching (Levy, 1997). Mishra and Koehler (2008) therefore regard teachers as designers because most technologies are designed for the corporate world and not for educational purposes.

\subsection{Turnitin}

Batani (2010) defines Turnitin as web-based software that is used to detect plagiarism in order to promote originality in student papers. Turnitin compares 
the submitted assignment of students with a huge database of internet sources and provides an originality report that is accessible to both the learner and the instructor. Davis and Carroll (2009) report that studies have investigated the impact of Turnitin on educational practice with the capacity of Turnitin as a deterrent to plagiarism being highlighted. According to Baker, Thornton, and Adams (2011), preliminary research suggests that teachers benefit from detecting plagiarisms because of the resultant decrease in plagiarism levels. Buckley and Cowap (2013) confirm that the teachers' workload decreases while there is also a reduction in the time spent on marking assignments and searching for instances of academic misconduct. In the main, the quality of the assignments improves and fewer incorrect referencing practices and fewer instances of plagiarism are found. According to Buckley and Cowap (2013), it would appear that Turnitin increases the learners' knowledge of plagiarism.

In general, Turnitin is positively received by teachers. The only difficulties usually involve inserting QuickMark Comments on the text while the second marking in GradeMark is often a challenge. According to Dahl (2007) learners welcomed Turnitin because of the identification of plagiarism and the electronic submission of assignments. However, Davis and Carroll (2009) also mention the controversies around Turnitin. Although it may help learners to avoid plagiarism, some academics are concerned that Turnitin is detracting from the teacher's responsibility to support learning. A few studies only have investigated the role of Turnitin in supporting learning, rather than guiding assessment, while even fewer studies have explored the role of formative feedback in supporting learning. Davis and Carroll (2009) investigated the role of formative feedback with the use of Turnitin to avoid plagiarism. The results showed that formative feedback on a one-to-one basis had a positive impact on reducing plagiarism. In addition, by using the Turnitin originality reports, the learners were more engaged and being given direct advice in a nonthreatening formative way. This approach appeared to be effective. Heckler (2013) emphasises that a supportive context is critical when implementing Turnitin.

However, some institutions were reluctant to embrace this perception of the use of Turnitin to avoid plagiarism because of a fear of losing learners. Nevertheless, the institution has a responsibility to educate learners not to plagiarise and it is essential that punitive measures are in place to deal with misconduct should a learner plagiarise. The implementation of Turnitin highlights an institution's commitment to academic integrity.

Rolfe (2011) found the use of Turnitin to be extremely valuable in terms of literacy development. Turnitin highlights the areas that require rewriting and it may be a useful tool in motivating learners to improve their literacy skills. The active engagement of learners that results from the use of Turnitin is also more 
beneficial for learning as compared to passive reception while the colourful report with clues which is provided is also more successful than mere written feedback. In addition, this approach also encourages the self-directed learning that leads to learners taking responsibility for their own learning (Rolfe 2011). However, instant feedback does not guarantee reduced plagiarism and learners still need to be educated. Rolfe (2011) reported that large numbers of learners had no problems in submitting draft assignments and receiving feedback. Comparisons between the initial assignment and the final submission showed improvements. Nevertheless, despite this improvement, the learners' citation skills deteriorated and the use of Turnitin did not have any impact on referencing.

Rolfe (2011) adds that, although Turnitin has the potential to lead learners to self-directed learning, he also noticed a lack of discipline in the self-directed learning of the learners. It is vital that self-directed learning is introduced in a supportive environment, especially if there is a low level of prior knowledge. Self-directed learning is successful when learners have a sense of responsibility and autonomy about their learning.

\subsection{Written Corrective Feedback (WCF)}

Ferris (2010) reports that empirical research on corrective feedback (CF) was rare before 1995. Writing was not emphasised in second language instruction. According to Sheen (2010), language learning was heavily influenced by the behaviourist views of language learning in the 1950s and 196os, and habit formation was emphasised. Errors were perceived as damaging to learning and they had no role to play in language acquisition. However, in the 1970s and 1980s, language acquisition, Krashen's theory (1982) was driven by positive evidence but, again, there was no room for CF. Ferris (2010) refers to the amount of material that was designed in the early 199os to address language issues in second language writing. Ferris (2010) advocates the contextualisation of written CF in the writing process. CF was prioritised to focus on frequent and serious writing error patterns and to address the individual needs of the learners. Ferris (2010) claims that the purpose of error correction is to provide strategies to guide learners to independent writing.

\subsection{Types of Feedback}

Alavi and Taghizadeh (2014) report on the verification and elaboration types of feedback which may be presented in the forms of implicit and/or explicit feedback. When implicit feedback is used, the learners have to correct their errors without any indication or pointing out of the errors in their output and, thus, the corrections are elicited from the learners themselves. On the other hand, with explicit feedback, the errors are pointed out to the learners. 
According to Wigglesworth and Storch (2012), feedback may be classified in terms of its explicitness or directness. The literature on written CF makes a clear distinction between direct and indirect feedback. In terms of direct feedback the teacher or another reader gives explicit corrections while, in indirect feedback, the learner's attention is drawn to an error but the learner has to correct the error. Second language writing researchers regard indirect feedback as a valuable means both to guide the learners to problem-solving and to provide opportunities for learners to take responsibility for their own learning progress (Ferris, 2010).

According to Ferris (2010), learners prefer indirect feedback to direct feedback. Another important fact to consider when providing feedback is first to determine the goal of the feedback. For example, the purpose or outcome of the writing activity influences the type of feedback. If the goal is to focus on a specific feature of the writing, then direct correction would be the most efficient. If, however, the goal is to assess the success of possible strategies for developing revision or editing processes, then indirect feedback that requires more effort or engagement on the part of the learner may be more efficient (Ferris, 2010). Ferris (2004) also recommends that teachers provide direct feedback for learners with low levels of second language proficiency because they do not have the ability to self-correct their errors.

Chandler (2003) discusses four different kinds of ways in which teachers may respond when they give WCF. These include:

- firstly, direct correction which, as mentioned previously, involves providing the correction to be made;

- secondly, indirect feedback which is done by underlining the error and providing a marginal description of the type of error;

- thirdly, and also indirectly, by merely giving a marginal description of the type of error; and,

- lastly, by simple underlining the error with no indication or description of the type of error (indirect).

The use of direct correction usually demonstrates a vast improvement in the number of errors because the learners simply rewrite the correction that the teacher had given. The underlining with a marginal description of the error proved to be the second most successful method with learners correcting more than two-thirds of their errors. The final method in terms of which the teachers merely pointed out the location of the error proved to be the least successful method although learners were still able to correct half of their errors. However, Chandler (2003) reports that the most effective way in which to gather evidence of learner improvement was with a different and new piece 
of writing that learners complete with fewer errors. In contradiction to the assertions of Ferris (2010) as described previously, it was found by Chandler (2003) that learners preferred direct feedback because it was much easier and quicker than indirect feedback. However, it was also found that the learners felt that the best way to learn from the mistake and to avoid a repeat of the mistake in the future was when the teacher underlined the mistake with a marginal description. The learners felt they learnt more by self-correcting.

\section{$5 \quad$ Adapted Conceptual Framework}

The framework used in this research adapts the Technological Pedagogical Content Knowledge (TPACK) Framework to incorporate one other theoretical framework. Technological pedagogical content knowledge (TPACK) is a conceptual theoretical framework and represents the interaction between content knowledge (CK), technological knowledge (TK), pedagogical knowledge (PK) and the transformation which is brought about when these three domains are combined. In order to teach effectively, teachers need to have knowledge of these three domains and also need to know how to integrate them successfully. Four domains arose out of the intersection of content knowledge, technological knowledge and pedagogical knowledge, namely, technological content knowledge (TCK), pedagogical content knowledge (PCK), technological pedagogical knowledge (TPK) and technological pedagogical content knowledge (TPACK) (Mishra \& Koehler, 2006).

Mishra and Koehler (2006, p. 1029) explain TPACK as:

... the basis of good teaching with technology and requires an understanding of the representation of concepts using technologies; pedagogical techniques that use technologies in constructive ways to teach content; knowledge of what makes concepts difficult or easy to learn and how technology can help redress some of the problems that students face; knowledge of students' prior knowledge and theories of epistemology; and knowledge of how technologies can be used to build on existing knowledge and to develop new epistemologies or strengthen old ones.

The TPACK Framework is inadequate on its own; therefore Vygotsky's theory is merged with the TPACK Framework to form a new conceptual framework that includes the two components of FAL learning, namely, the content, that is, the grammar that forms the basis for second language acquisition, and the skill, that is, second language acquisition in the zone of proximal development of the 
learners. The primary task of an Afrikaans FAL teacher is to teach and facilitate the acquisition of Afrikaans FAL. The framework that underpins language acquisition is the FAL content and the skills. The curriculum skills consist of learners communicating accurately and appropriately; using the additional language for academic learning across the curriculum; listening, speaking, writing and presenting with confidence and enjoyment; thinking independently and analytically; being able to express their experiences and findings orally and in writing; using the additional language to access and manage information across the curriculum; and becoming critical and creative thinkers (National Curriculum Statement Grade R-12, 2012). FAL constitutes the content in the form of grammar and language rules that learners have to master (CK).

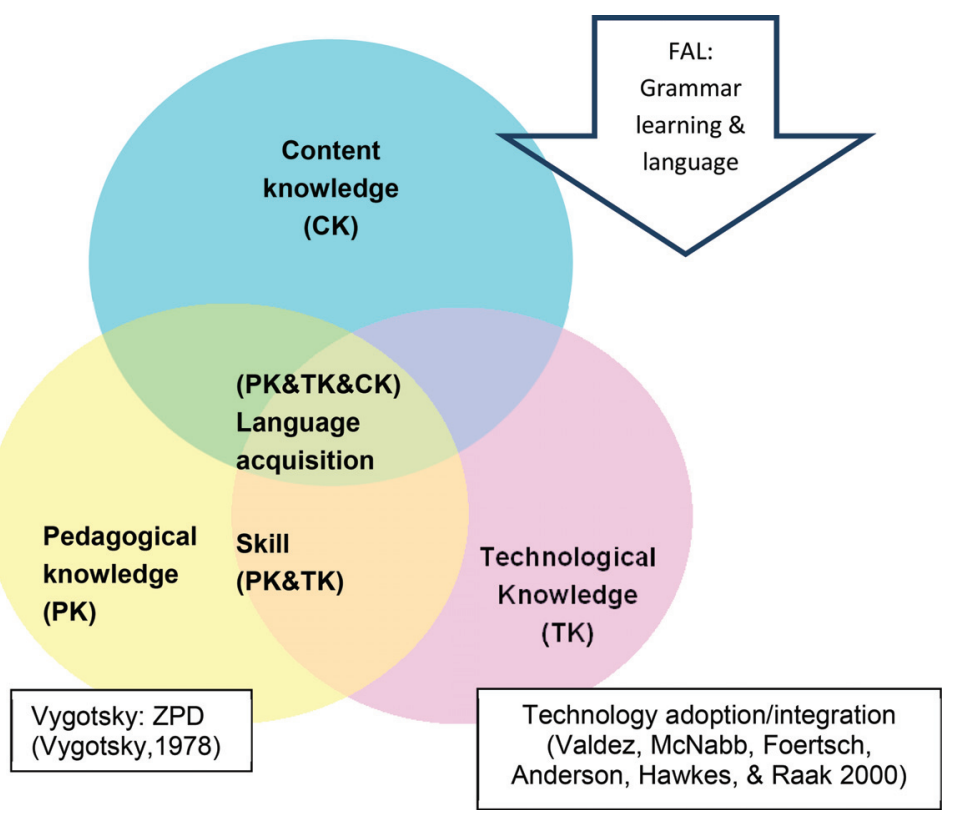

FIGURE 2.1 Adapted conceptual framework (Sujee, 2015)

The biggest challenge in this particular context is the great variation in language skills and attitudes in the learners as a result of the economic and political changes that have taken place in South Africa. The learners have become more diverse, as they come from other countries as well as South Africa, and learners from previously disadvantaged groups are also being enrolled. In addition, the boarding facilities are in high demand because increasingly parents are working overseas or have demanding jobs that require long hours. As a result, the teachers were faced with learners with different levels of Afrikaans proficiency. 
In order to provide each learner with the best chance of success and to support each to surpass his/her own zone of proximal development, as suggested by Vygotsky (1978), teachers should address learners' individual needs. According to Vygotsky (1978), the zone of proximal development is the distance between what the learner knows and what the learner could potentially know. Vygotsky (1978) focused on the way in which humans function when placed in a certain problem situation, with the tools to solve the problem. Vygotsky (1978) views learning as a social process within a certain context and thus social interaction is key to learning. By interacting with the teacher and capable peers, learners learn from one another in a social context and acquire knowledge and skills. Therefore teachers should provide powerful artefacts and learning opportunities for collaboration with experts in order to bridge the distance between learners' current levels of understanding and their potential levels. Vygotsky therefore informs the pedagogy needed to teach this subject in this context and represents the PK knowledge in Fig. 2.1.

By providing individualised feedback to each individual learner, technology makes individual learning possible, but only if it is ubiquitous and is adopted by all role players. The third component of the framework is therefore technology (TK). Technology can be used to transform content in order for learners to have a better understanding of the subject matter (Mishra \& Koehler, 2006). Teachers must therefore choose the correct technology based on pedagogical principles that can help the learner to grasp the content (Levy, 1997; Murray \& Barnes, 1998). Technology is thus merely a teaching tool and, as such, must be used to integrate the learning and teaching methods with the available resources. Gordon et al. (2009) describe the "ideal" learning environment as an environment in which a more individualised approach is adopted that includes collaborative cross-curricular teaching and good leadership that builds on the vision of school development and encourages teamwork. The benefits of technology integration far surpass the challenges, therefore, teachers need to look for solutions to overcome these challenges (Golonka, Bowles, Frank, Richardson, \& Freynik, 2014).

Insufficient access to technology, and lack of time and technology skills, are factors that prevent teachers from integrating technology in the classroom (Tondeur et al., 2012). In addition, learners may become frustrated with software and hardware that does not work or has not been installed properly, distractions from the learning task and teachers ignoring the pedagogical purpose of the task (Golonka et al., 2014). According to Annetta (2010), there is generally not enough commitment from teachers and learners to integrate technology. Teachers therefore need to develop new tools and applications, using advanced technologies to enhance teaching and learning. Teachers 
with a good TPACK framework apply technology as an integrative part of the teaching process.

Krashen (1982) clearly distinguishes between language learning and language acquisition. Language acquisition occurs subconsciously in natural and meaningful interactions, while language learning is a conscious process of acquiring knowledge about the language, for example grammar rules. Language skill can be taught in the intersection between pedagogy and technology if technology is well used (TKPK). However, acquisition also requires a solid foundation of content in the form of grammar and language knowledge and rules. Part of acquisition is therefore situated at the intersection of all three knowledges, namely, TPACK.

This adapted conceptual framework guided this inquiry and provided the lens for this investigation to direct and manage the complexity of the digital era.

This research study is an in-depth understanding of a group of girls in Grade 11 and the effect of technology on their learning in an Afrikaans First Additional Language classroom. The purpose of the study is to explore and describe the effect of computer technology in a multilingual language class.

Case study researchers focus on an activity which involves individuals. As such, they are interested in describing the activities of the group in order to gain an in-depth understanding of the case in question (Creswell, 2008). According to Griffee (2012), either a quantitative or a qualitative approach may be applied to case studies. Having said that, a qualitative approach was followed whereby an understanding of the phenomenon in question was obtained through the eyes of the participants and by collecting rich, in-depth data on the participants' subjective experiences and how they construct the social world in their natural environment (Nieuwenhuis, 2007). In addition, Hine (2005) adds another type of case study to the list and situates the case study of netnography under the umbrella of online ethnography: online netnography involves observing the naturally occurring "posting" and "threads" in online forum and interviews within an online community. The requisite data may be collected online as well as offline. In view of the fact that the focus of this study was the impact of technology on the learning of learners within an online community, the researcher selected this type of case study as the most appropriate for the purposes of the study.

As a teacher at this sampled school, the researcher had ready access to learners, teachers and the technician, making this a convenient sample. 


\begin{tabular}{|c|c|c|c|c|c|c|}
\hline \multirow[t]{2}{*}{ Participant } & \multicolumn{6}{|c|}{ Medium of instruction in language } \\
\hline & Race & $\begin{array}{l}\text { Pre-primary } \\
\text { schooling }\end{array}$ & $\begin{array}{l}\text { Primary } \\
\text { schooling }\end{array}$ & $\begin{array}{l}\text { Used at } \\
\text { home }\end{array}$ & $\begin{array}{l}\text { Used in } \\
\text { social } \\
\text { circles }\end{array}$ & $\begin{array}{l}\text { Other } \\
\text { languages } \\
\text { in order of } \\
\text { proficiency }\end{array}$ \\
\hline
\end{tabular}

\begin{tabular}{|c|c|c|c|c|c|c|}
\hline 1 & White & English & English & English & English & Afrikaans \\
\hline 2 & White & English & English & English & $\begin{array}{l}\text { English } \\
\text { Afrikaans }\end{array}$ & Afrikaans \\
\hline 3 & White & English & English & $\begin{array}{l}\text { English/ } \\
\text { Portuguese }\end{array}$ & English & Afrikaans \\
\hline 4 & White & English & English & $\begin{array}{l}\text { Afrikaans/ } \\
\text { English }\end{array}$ & $\begin{array}{l}\text { Afrikaans/ } \\
\text { English }\end{array}$ & $\begin{array}{l}\text { French } \\
\text { Afrikaans }\end{array}$ \\
\hline 5 & White & English & English & English & $\begin{array}{l}\text { English } \\
\text { Afrikaans }\end{array}$ & Afrikaans \\
\hline 6 & Mixed & English & English & $\begin{array}{l}\text { Southern } \\
\text { Sotho }\end{array}$ & $\begin{array}{l}\text { English, } \\
\text { Sotho, } \\
\text { Tswana }\end{array}$ & $\begin{array}{l}\text { Tswana } \\
\text { English } \\
\text { Xhosa } \\
\text { Afrikaans }\end{array}$ \\
\hline 7 & White & English & English & English & English & Afrikaans \\
\hline 8 & Black & Setswana & English & Setswana & $\begin{array}{l}\text { English/ } \\
\text { Setswana }\end{array}$ & $\begin{array}{l}\text { Sotho } \\
\text { English } \\
\text { Zulu } \\
\text { Afrikaans }\end{array}$ \\
\hline 9 & White & Afrikaans & English & $\begin{array}{l}\text { English/ } \\
\text { German }\end{array}$ & English & $\begin{array}{l}\text { German } \\
\text { Afrikaans }\end{array}$ \\
\hline 10 & White & English & English & English & English & Afrikaans \\
\hline 11 & Asian & English & English & English & English & Afrikaans \\
\hline 12 & White & English & English & $\begin{array}{l}\text { English/ } \\
\text { Greek }\end{array}$ & English & Afrikaans \\
\hline 13 & White & English & English & English & English & Afrikaans \\
\hline 14 & White & English & English & English & English & Afrikaans \\
\hline 15 & White & English & English & $\begin{array}{l}\text { English/ } \\
\text { Afrikaans }\end{array}$ & $\begin{array}{l}\text { English/ } \\
\text { Afrikaans }\end{array}$ & $\begin{array}{l}\text { English/ } \\
\text { Afr HL }\end{array}$ \\
\hline 16 & Black & English & English & Shona & English & $\begin{array}{l}\text { Zulu } \\
\text { English } \\
\text { Afrikaans }\end{array}$ \\
\hline
\end{tabular}




\begin{tabular}{lllllll}
\hline Participant & \multicolumn{5}{c}{ Medium of instruction in language } \\
\cline { 2 - 6 } & Race & $\begin{array}{l}\text { Pre-primary } \\
\text { schooling }\end{array}$ & $\begin{array}{l}\text { Primary } \\
\text { schooling }\end{array}$ & $\begin{array}{l}\text { Used at } \\
\text { home }\end{array}$ & $\begin{array}{l}\text { Used in } \\
\text { social } \\
\text { circles }\end{array}$ & $\begin{array}{l}\text { Other } \\
\text { languages } \\
\text { in order of } \\
\text { proficiency }\end{array}$ \\
\hline 17 & Black & English & English & Ndebele/ & English & English \\
& & & & English & Afrikaans \\
18 & White & English & English & English & English & Afrikaans \\
\hline 19 & White & English & English & English & English & Afrikaans \\
\hline
\end{tabular}

As indicated in Table 2.1, the class includes diverse learners with different levels of proficiency in Afrikaans. In addition, the learners differ in respect of their backgrounds, cultures, race and the social circles in which they move and interact. Their social circles influence their level of proficiency in Afrikaans FAL. Below is the breakdown of the teachers and the technician in Table 2.2. The participants were all female.

Focus group discussions in a chat room with the First Additional Language teachers and the technician were important because the researcher believed they would be able to shed some light on the influence of the integration of relevant computer technologies on teaching and learning in a multilinguistic language class and the learners' perceptions of the effective use of computer technology in a multilinguistic language class. These female teachers have all taught at the school since the school incorporated technology into the curriculum. The three Afrikaans First Additional Language teachers, the one Sepedi First Additional Language teacher and the female technician also all worked in the same school environment and were able to answer the questions on the relevant technology in the First Additional Language classrooms, the challenges that were faced with the integration of technology as well as the potential use of technology in addressing the individual needs of the learners. The technician's input was valuable for the emerging technologies as well as the circumstances which are beneficial for effective technology integration.

Technology was deliberately integrated into the lessons with the sampled class. The researcher used the Smart Board, PowerPoint, Word and Excel software programs extensively in the past and introduced new technology such as the Smart Response System, Voki characters, Turnitin, chat rooms, blogging on Kid blog and YouTube. 


\begin{tabular}{|c|c|c|c|c|c|}
\hline & Teacher 1 & Teacher 2 & Teacher 3 & Teacher 4 & Technician \\
\hline $\begin{array}{l}\text { Position held at } \\
\text { the school }\end{array}$ & Teacher & Teacher & $\begin{array}{l}\text { Subject Head: } \\
\text { Sepedi }\end{array}$ & $\begin{array}{l}\text { Deputy } \\
\text { Principal }\end{array}$ & $\begin{array}{l}\text { Information } \\
\text { Technology } \\
\text { Specialist }\end{array}$ \\
\hline \multicolumn{6}{|l|}{ Teaching } \\
\hline $\begin{array}{l}\text { Subject at the } \\
\text { school }\end{array}$ & $\begin{array}{l}\text { Afrikaans } \\
\text { FAL }\end{array}$ & $\begin{array}{l}\text { Afrikaans } \\
\text { FAL }\end{array}$ & Sepedi FAL & $\begin{array}{l}\text { Afrikaans } \\
\text { FAL }\end{array}$ & $\begin{array}{l}\text { Information and } \\
\text { communications } \\
\text { Technician }\end{array}$ \\
\hline $\begin{array}{l}\text { Experience } \\
\text { (years) }\end{array}$ & 18 & 7 & 30 & 30 & 8 \\
\hline $\begin{array}{l}\text { Experience } \\
\text { at the school } \\
\text { (years) }\end{array}$ & 9 & 7 & 10 & 9 & 8 \\
\hline Qualifications & BEd (Hons) & B Ed & $\begin{array}{l}\text { MA in African } \\
\text { Languages }\end{array}$ & $\begin{array}{l}\text { MA } \\
\text { Languages }\end{array}$ & $\mathrm{A}+\mathrm{N}+\mathrm{MCSC}$ \\
\hline $\begin{array}{l}\text { Main } \\
\text { specialisation } \\
\text { subjects }\end{array}$ & $\begin{array}{l}\text { Afrikaans } \\
\text { English } \\
\text { Mathematics } \\
\text { History }\end{array}$ & Afrikaans & Sepedi & $\begin{array}{l}\text { Afrikaans, } \\
\text { Zulu }\end{array}$ & $\mathrm{N} / \mathrm{A}$ \\
\hline $\begin{array}{l}\text { First } \\
\text { Additional } \\
\text { Language } \\
\text { teaching } \\
\text { experience } \\
\text { (years) }\end{array}$ & 16 & 7 & 30 & 30 & $\mathrm{~N} / \mathrm{A}$ \\
\hline $\begin{array}{l}\text { Experience in } \\
\text { teaching with } \\
\text { technology } \\
\text { (years) }\end{array}$ & 9 & 7 & 13 & 9 & $\mathrm{~N} / \mathrm{A}$ \\
\hline
\end{tabular}

Learners used their laptops to do essay writing. In the feedback, the researcher used different colours to highlight errors in word structure, sentence structure and punctuation, as well as for any outstanding work done as illustrated in Fig. 2.2.

The feedback worked in the following way: when an error was identified, it was highlighted according to the different error categories mentioned above. A 'quick mark' with a full explanation of the applicable grammar 


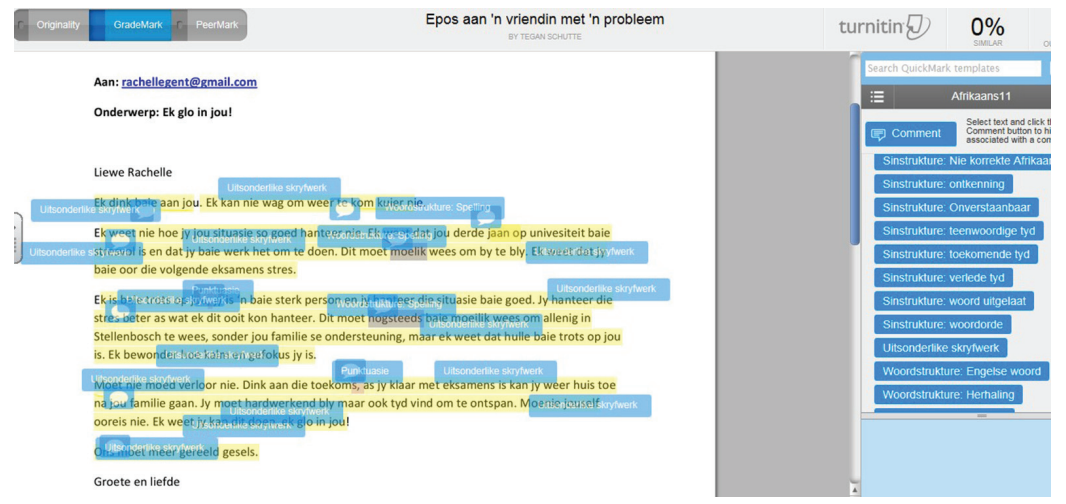

FIGURE 2.2 Example of an assignment marked using the quick mark comments

rules was also provided as these rules are an integral part of the Afrikaans FAL curriculum. Yellow indicated outstanding writing, pink highlighted a sentence structure error, blue showed a word structure error and punctuation errors were highlighted in purple. Learners were provided with feedback as written individual comments and audio individual comments, enhancing differentiation with the aid of technology.

The empirical component of the study included anonymous online discussions in a blog on the part of the learners, observations of the learners when they were engaging in the online discussions, class observations via video recordings of five lessons, five semi-structured interviews with the learners via email, two focus group discussions with the staff in a chat room and the written texts of the learners on the Turnitin software programme in an e-portfolio. The initial questions for the semi-structured interviews were broad questions on the learners' personal beliefs about the role of technology in the schools, their computer proficiency and the use of technology. The responses to these questions informed the subsequent questions as the study progressed (Creswell, 2008, p. 56). The questions focused on the sub-questions which were the relevance of computer technology for teaching and learning in a multilinguistic language class in the 21st century, challenges encountered when integrating computer technology in a multilinguistic class and how technology could be utilised to address every learner's individual learning needs. Some examples include:

1 Please tell me what are your personal beliefs about the role of technology in your class?

2 If you could make a recommendation to other learners and teachers who wanted to do more with technology in their classrooms, what recommendation would you make? 
3 Name at least three advantages of technology use for you in the Afrikaans First Additional Language classroom.

The learners' first assignment for their e-portfolio on the Turnitin software programme was to design a curriculum vitae (CV) for themselves. This served as a short transactional piece of writing only to enable the learners to accustom themselves to Turnitin. The second assignment was more challenging than the first and was an essay. The essay was written as process writing. Process writing involves the learners being given more than one opportunity to write a creative piece. The teacher identified and showed learners the mistakes they had made without correcting the mistakes for them. The learners received the feedback back from the teacher and then, guided by the individual feedback, tried to correct their own mistakes. Then, if necessary, their peers helped some of the learners to correct their mistakes. When an error was identified, the teacher scaffolded the learner to correct it in a contingent manner, offering just enough assistance to guide the learner to examine her own mistake, recognise it and correct it. The aim of this process was to enable the learner to assume responsibility for her own learning, to make a conscious decision to help herself and, thus, to assume autonomy in the learning process. The learners then uploaded their final, corrected essays for assessment. Finally they were asked to write comments of their experience of Turnitin on the blog. These comments were used as data for the purpose of the study.

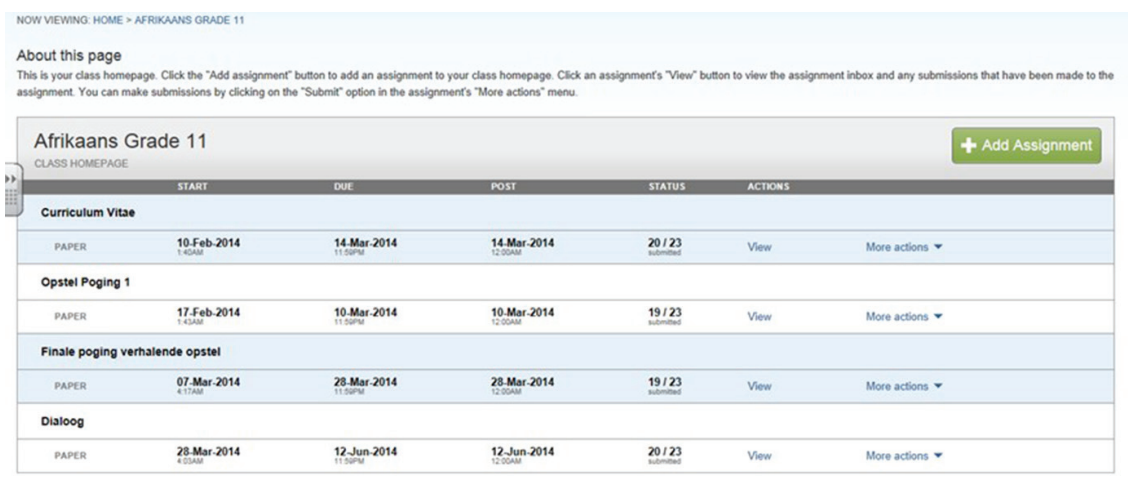

FIGURE 2.3 Example of an e-portfolio on Turnitin

The third assignment was a dialogue. Learners were given the opportunity to choose their own topics, thus allowing them to take responsibility for their learning and to encourage creativity. The final transactional writing piece was an e-mail. 
In addition, each learner's progress could be monitored with the Grade Mark feature of Turnitin. The researcher used ATLAS.ti to transcribe and analyse the data sources. The data analysis in this netnographic case study was primarily an inductive process where the data was coded, using open coding and in vivo coding. The qualitative data was electronically saved and transcribed. Member checks ensured that the information was verified by the participants. The adapted conceptual framework was used as a lens to interpret the data sources.

Results: Technological, pedagogical and content knowledge (TPACK)

\subsection{Addressing Learners' Individual Needs}

Learners reported on the effectiveness of Turnitin for addressing the individual needs of learners. Turnitin is very learner-centred because the teacher provides guidance by means of individual WCF; thus the Turnitin experience was described by most learners as a personalised learning experience focused on their individual needs. In addition, many of the learners regarded Turnitin as one of the most successful integrations of technology in the FAL classroom and mentioned that it had helped them to improve their Afrikaans FAL skills. Learners reported that their writing skills and language had improved with Turnitin. Learners were provided with feedback in a written individual comment and an audio individual comment, making differentiation possible with the aid of technology. Learners used earphones to listen to the individual audio comment in Turnitin. In this way, individual needs were addressed without making any sounds that could have disturbed the other learners in the class.

\subsection{Active Engagement with Feedback}

Engaging with feedback allows learners to learn from their mistakes and it also prevents them from making the same mistakes again. Turnitin provides an analysis of the types of error that occur. The types of error made by every learner, as well as the progress made or lack thereof, are very useful for setting individual goals for learners. The teacher can follow the learner's progress via the internet and collect valuable information about her progress as indicated in Fig. 2.4.

The learners then engage with the feedback and correct their errors. The number of errors had decreased in comparison with the first draft of the narrative essay which shows an improvement. Turnitin is a very valuable tool for feedback through the Grade Mark option. In addition, the quick 


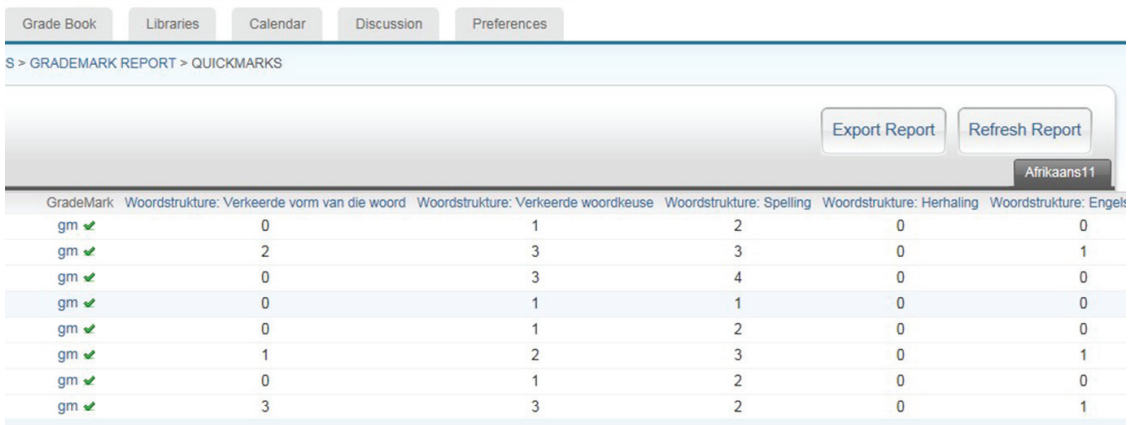

FIGURE 2.4 Analysis of the errors of all the learners on one assignment

mark comment is viewed by the educators as a great asset because it helps with the marking and it gives more weight and depth to the feedback. Saved quick mark comments can be quickly re-used or existing comments can be altered and the typing of comments goes more quickly than the traditional writing of comments. Having assessments online meant that no assignments were lost and there was no need to transport them between home and the office.

It is also very easy to convert the learners' marks into graphs (Fig. 2.5). Learners can compare their own assignments and track their progress or compare it to the whole class.

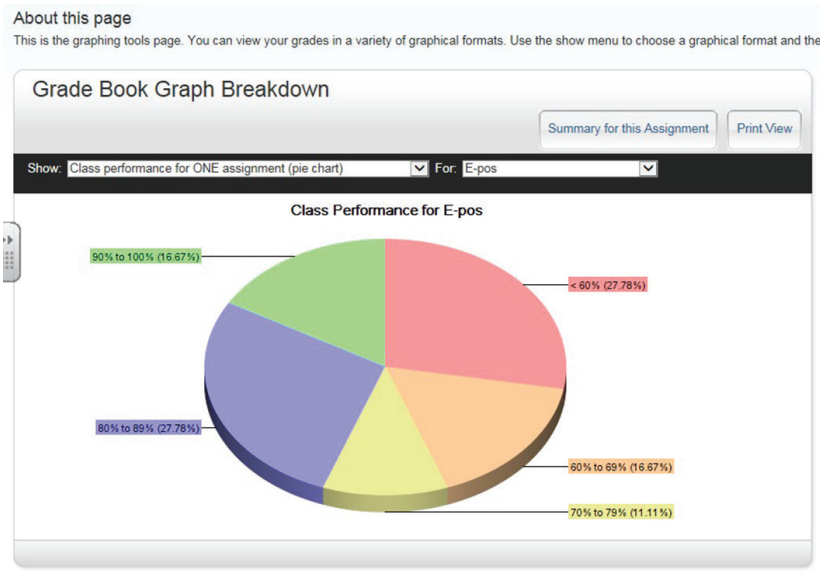

FIGURE 2.5 Overview of the entire class's performance on the e-mail

\subsection{Collaborative Learning on the Discussion Board}

By initiating a discussion opportunity on the discussion board (Fig. 2.6), learners reported that they learnt from other learners' mistakes and they were 
not embarrassed to share their mistakes with and learn from other learners because everyone was involved in the activity. Collaborative learning was taking place in the discussion board. Learners felt that they were not the only ones making mistakes but that everybody was helping each other to correct their mistakes. In addition, when learners correct mistakes in their word and sentence structure and in punctuation they are also learning language. They are thus forced to integrate grammar with creative writing, making the grammar rules so much more meaningful.

Learners mentioned that communication between teacher and learner and among the learners themselves had improved.

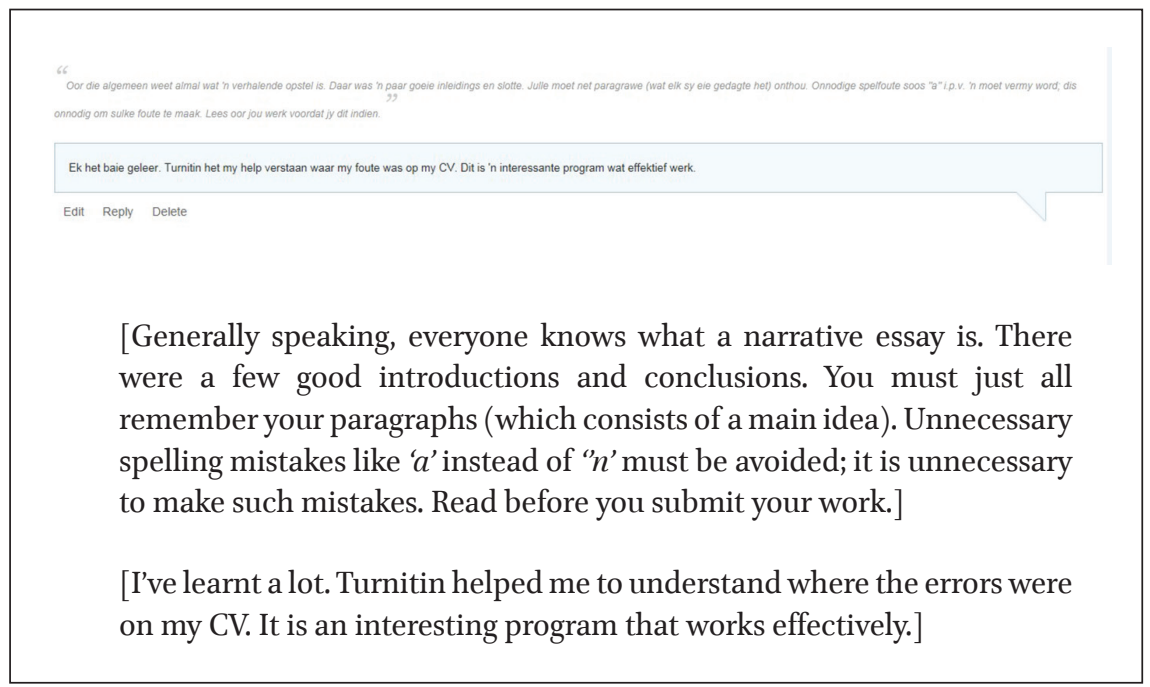

FIGURE 2.6 Discussion board on Turnitin

Interaction on the discussion board emphasises Vygotsky's (1978) belief that interaction is key to learning. This coincides with Brown's (1977) statement that a person who is willing to make mistakes is more likely to experience success in second language learning. Accordingly, learners stated that they appreciated the individual feedback that is provided with Turnitin, as is reflected in the following statement:

I successfully used technology in Afrikaans when we wrote our transactional essay on our computers and submitted it to Turnitin. It was good because we got personal feedback on our errors. (p. 15)

It was interesting to note that one learner reflected on her own learning which the teacher found very valuable for her progress. She reflected that 
she thought her vocabulary was insufficient to express her thoughts. Another error that was mentioned was punctuation. One learner reported that she learned that ' $n$ ' is always written with a small letter. These are some of the small gaps that can be filled by such a collaborate discussion. Other girls learned from her comment on the discussion board. Learners frequently use English words because English is their medium of instruction and making them aware of these words helps them to focus on using the correct Afrikaans words. Words such as "hey", "cool", "hello" and "America", just to name a few, were mentioned.

Learners also mentioned spelling mistakes. The teacher had to intervene and give the correct spelling of "foute" because some of the stronger learners were spelling the words incorrectly. The weaker learners learn from the stronger learners; therefore their word order and spelling must be correct in order for other learners to learn the correct spelling and word order. Other common spelling mistakes mentioned were: "kaans", "kompiteer", "defnetief", "problem", etc.

One learner mentioned that she made a mistake when she used the negative form. She forgot that "ooit" change to "nooit". This is a typical example of the disintegration between the grammar component and the writing component.

One of the reflections on the discussion board besides the errors mentioned above was that the learner realised that she has to edit her own work first before submitting it to avoid unnecessary mistakes.

Furthermore, in a context that allows interaction and communication, learning is viewed as a social process. In this case study, the classroom and the online environment comprised the social context for learning, allowing learners to work co-operatively. The aim of the discussion board is for the learners to learn from each other. It is also important for the teacher to summarise the main points at the end of the discussion.

\subsection{Integration of Content, Pedagogy and Technology}

A major obstacle in second language acquisition is the fact that learners often fail to see the connection between the oral presentations, writing and grammar structures. They view these as being separate sections of language learning while in fact they are integrated. Learners do not grasp the concept that what you learn about grammar structures must be applied when you do oral presentations, write a creative piece or communicate in the target language and thus do not integrate the different sections. By using the quick mark comments on Turnitin, learners are forced to integrate writing and grammar structures when they correct their word and sentence structure 
errors and errors in punctuation. This is one of the great advantages of Turnitin and can contribute to the success of language teaching in the FAL classroom. Another great advantage is that the teacher can provide feedback on Turnitin in any language, because the teacher creates personalised feedback. Having said that, it is also possible to use Turnitin for feedback in any subject, even Art, because of the customised feedback. Turnitin was used in this study as an effective formative assessment tool, though its primary purpose is to detect plagiarism. The use of Turnitin has given rise to a different method of communication and has resulted in spontaneous collaboration between all participants interacting in the target language on the discussion board of Turnitin. This study proves how Turnitin can be utilised in any module or subject because the quick mark comments can be customised. Turnitin proved to be of value to the learners as they want to know where they need to improve and they prefer engaging with written corrective feedback (WCF) and correcting their errors to engagement with no feedback at all. Similarly, this feedback can be given to learners in any subject, any language and any country. The learners want to interact with other learners with different cultures, background, social circles, etc. and learn from them. By actively engaging in their individual written corrective feedback (WCF), learners reflect on their individual mistakes and learn from these mistakes. Thus, learners take ownership of their own learning which results in self-directed learning. Learners are able to monitor their individual progress with the help of the teacher and using Turnitin's Grade Mark features. In addition, individual learners are provided with support from their more capable peers and the teacher on the discussion board. Another great advantage is that the teacher can provide feedback on Turnitin in any language, because the teacher creates personalised feedback.

\section{Conclusion}

Learners learn through interaction and collaboration with other learners and, thus, knowledge is a human product. Both the classroom and the online environment in this case study were the social context for learning and enabled the learners to work co-operatively. The discussion board of Turnitin provided a platform for help from capable peers and the teacher (Vygotsky, 1978). Learners were able to ask for help individually while any capable learner or the teacher could help a learner online. The learners acquired the language in a natural setting and all the learners were eager to participate because 
everyone formed part of the discussion board. In addition, the learners were not afraid to make mistakes because each learner was involved and the focus of the discussion board was on solutions for errors made (Krashen, 1982). The learners appreciated the WCF on Turnitin because it helped them identify areas in which they needed to improve while it also highlighted their strengths. Learners learn from one another in a social context and, with the help of the teacher and capable peers, they acquire knowledge and skills through interaction. Thus, their learning is facilitated by social interaction and the learners take responsibility for their own learning by engaging in co-operative and authentic learning tasks and activities. Krashen (1982) views the acquisition of a language in a relaxed, natural environment in which the learners want to listen or contribute as the easiest way of learning a language. Technology may provide such platforms for language learning with learners being exposed both to the target language and to opportunities for interaction in the target language. In addition, learners can also be provided with opportunities to write in the target language (Chapelle, 2009). Technology supplies learners with multiple forms of rich input and interaction.

\section{References}

Alavi, S. M., \& Taghizadeh, M. (2014). Dynamic assessment of writing: The impact of implicit/explicit mediations on L2 learners' internalization of writing skills and strategies. Educational Assessment, 19(1), 1-16. doi:10.108o/10627197.2014.869446

Angeli, C., \& Valanides, N. (2009). Epistemological and methodological issues for the conceptualization, development, and assessment of ICT-TPCK: Advances in Technological Pedagogical Content Knowledge (TPCK). Computers \& Education, 52(1), 154-168.

Annetta, L. A., Cheng, M.-T., \& Holmes, S. (2010). Assessing twenty-first century skills through a teacher created video game for high school biology students. Research in Science \& Technological Education, 28(2), 101-114.

Baker, R. K., Thornton, B., \& Adams, M. (2011). An evaluation of the effectiveness of turnitin.com as a tool for reducing plagiarism in graduate student term papers. College Teaching Methods \& Styles Journal (CTMS), 4(9), 1-4.

Barr, J. D., \& Gillespie, J. H. (2003). Creating a computer-based language learning environment. ReCALL15, 1, 68-78.

Batane, T. (2010). Turning to Turnitin to fight plagiarism among university students. Educational Technology \& Society, 13(2), 1-12.

Bruett, K. (2006). Why American business demands twenty-first century skills: An industry perspective. In E. Schwarz \& K. Kay (Eds.), New directions for youth 
development: The case for twenty-first century learning (pp. 25-30). San Francisco, CA: Wiley.

Buckley, E., \& Cowap, L. (2013). An evaluation of the use of Turnitin for electronic submission and marking and as a formative feedback tool from an educator's perspective. British Journal of Educational Technology, 44(4), 562-570. doi:10.1111/ bjet.12054

Carneiro, R., \& Gordon, J. (2013). Warranting our future: Literacy and literacies. European Journal of Education, 48(4), 476-497. doi:10.1111/ejed.12055

Carstens, A. (2012). Using literacy narratives to scaffold academic literacy in the bachelor of education: A pedagogical framework. Journal for Language Teaching= Tydskrif vir Taalonderrig, 46(2), 9-25.

Cervi, L. M. P., Paredes, O., \& Tornero, J. (2010). Current trends of media literacy in Europe:An overview. InternationalJournal of DigitalLiteracy and Digital Competence $(I J D L D C), 1(4), 1-9$.

Chandler, J. (2003). The efficacy of various kinds of error feedback for improvement in the accuracy and fluency of L2 student writing. Journal of Second Language Writing, $12(3), 267-296$.

Chapelle, C. A. (2009). The relationship between second language acquisition theory and computer-assisted language learning. MODL the Modern Language Journal, 93, 741-753.

Chen, D., Wu, J., \& Wang, Y.-M. (2011). Unpacking new media literacy. Journal on Systemics, Cybernetics and Informatics, 9(2), 84-88.

Coiro, J. (2003). Exploring literacy on the internet: Reading comprehension on the internet: Expanding our understanding of reading comprehension to encompass new literacies. The Reading Teacher, 56(5), 458-464. doi:10.2307/20205224

Cope, B., \& Kalantzis, M. (200o). Multiliteracies: Literacy learning and the design of social futures. London: Psychology Press.

Cramer, S. R. (2007). Update your classroom with learning objects and twenty-firstcentury skills. Clearing House, $80(3), 126-132$.

Creswell, J. (2008). Educational research: Planning, conducting and evaluating quantitative and qualitative research. Upper Saddle River, NJ: Pearson.

Dahl, S. (2007). Turnitin. Active Learning in Higher Education, 8(2), 173-191.

Danzak, R. L. (2011). Defining identities through multiliteracies: EL teens narrate their immigration experiences as graphic stories. Journal of Adolescent \& Adult Literacy, 55(3), 187-196. doi:10.1002/JAAL.0oo24

Davis, M., \& Carroll, J. (2009). Formative feedback within plagiarism education: Is there a role for text-matching software? International Journal for Educational Integrity, $5(2), 5^{8-70}$.

Department of Basic Education. (2012). National curriculum statement grades $R-12$. Pretoria: Government printers. 
Devereux, L., \& Wilson, K. (2008). Scaffolding literacies across the bachelor of education program: An argument for a course-wide approach. Asia-Pacific Journal of Teacher Education, 36(2), 121-134.

Ferris, D. R. (2004). The "grammar correction" debate in L2 writing: Where are we, and where do we go from here? (and what do we do in the meantime ...?). Journal of Second Language Writing, 13(1), 49-62. doi:http://dx.doi.org/10.1016/ j.jslw.2004.04.005

Ferris, D. R. (2010). Second language writing research and written corrective feedback in SLA. Studies in Second Language Acquisition, 32(2), 181-201. doi:10.1017/ So27226310999049o

Golonka, E. M., Bowles, A. R., Frank, V. M., Richardson, D. L., \& Freynik, S. (2014). Technologies for foreign language learning: A review of technology types and their effectiveness. Computer Assisted Language Learning, 27(1), 70-105. doi:10.1080/095 88221.2012.700315

Gordon, J., Halasz, G., Krawczyk, M., Leney, T., Michel, A., Pepper, D., \& Wiśniewski, J. (2009). Key competences in Europe: Opening doors for lifelong learners across the school curriculum and teacher education (CASE Network Report No. 87). Warsaw: Center for Social and Economic Research.

Greene, J. A., Yu, S. B., \& Copeland, D. Z. (2014). Measuring critical components of digital literacy and their relationships with learning. Computers \& Education, 76 , 55-69. Retrieved from http://dx.doi.org/10.1016/j.compedu.2014.03.008

Griffee, D. T. (2012). An introduction to second language research methods: Design and data. Berkeley, CA: TESL-EJ Publications.

Heckler, N. C., Rice, M., \& Bryan, C. H. (2013). Turnitin systems: A deterrent to plagiarism in college classrooms. Journal of Research on Technology in Education (International Society for Technology in Education), 45(3), 229-248.

Hine, C. (2005). Virtual methods: Issues in social research on the internet. New York, NY: Berg Publishers.

Hobbs, R., Felini, D., \& Cappello, G. (2011). Reflections on global developments in media literacy education: Bridging theory and practice. The Journal of Media Literacy Education, 3(2), 66-73.

Huffaker, D. (2005). The educated blogger: Using weblogs to promote literacy in the classroom. AACE Journal, 13(2), 91-98.

Jewitt, C. (2008). Multimodality and literacy in school classrooms. Review of Research in Education, 32(1), 241-267.

Kimmons, R. (2014). Social networking sites, literacy, and the authentic identity problem. TechTrends: Linking Research \& Practice to Improve Learning, 58(2), 93-98. doi:10.1007/s11528-014-0740-y

Krashen, S. (1982). Principles and practice in second language acquisition. Oxford: Pergamon Press. 
Levy, M. (1997). Theory-driven CALL and the development process. Computer Assisted Language Learning, 10(1), 41-56.

Mishra, P., \& Koehler, M. (2006). Technological pedagogical content knowledge: A framework for teacher knowledge. The Teachers College Record, 108(6), 1017-1054.

Mishra, P., \& Koehler, M. J. (2008, March 24-28). Introducing technological pedagogical content knowledge. Paper presented at the annual meeting of the American Educational Research Association, New York, NY.

Murray, L., \& Barnes, A. (1998). Beyond the "wow" factor: Evaluating multimedia language learning software from a pedagogical viewpoint. System, 26(2), 249-259.

Nelson, J., Christopher, A., \& Mims, C. (2009). TPACK and web 2.0: Transformation of teaching and learning. TechTrends: Linking Research \& Practice to Improve Learning, 53(5), 80-87. doi:10.1007/s11528-oo9-0329-z

Nelson, K. (2008). Teaching in the digital age: Using the internet to increase student engagement and understanding (2nd ed.). Thousand Oaks, CA: Corwin Press.

Newfield, D., \& Maungedzo, R. (2006). Mobilising and modalising poetry in a Soweto classroom. English Studies in Africa, 49(1), 71-93.

Nieuwenhuis, J. (2007). Qualitative research designs and data gathering techniques. In K. Maree (Ed.), First steps in research (pp. 69-97). Pretoria: Van Schaik Publishers.

Owen-Smith, M. (2012). Overcoming inequality in South Africa through multi-bilingual education: A set of teaching methodologies. Paper presented at the Conference 'Towards Carnegie III', University of Cape Town, Cape Town.

Rolfe, V. (2011). Can Turnitin be used to provide instant formative feedback? British Journal of Educational Technology, 42(4), 701-710.

Sheen, Y. (2010). Differential effects of oral and written corrective feedback in the ESL classroom. Studies in Second Language Acquisition, 32(2), 203-234.

Sujee, E. (2015). The effect of computer technology on learning in a multilinguistic language class (Doctoral dissertation). University of Pretoria, Pretoria.

Tapscott, D. (1998). Growing up digital (Vol. 302). New York, NY: McGraw-Hill.

Tondeur, J., van Braak, J., Sang, G., Voogt, J., Fisser, P., \& Ottenbreit-Leftwich, A. (2012). Preparing pre-service teachers to integrate technology in education: A synthesis of qualitative evidence. Computers \& Education, 59(1), 134-144.

Wigglesworth, G., \& Storch, N. (2012). What role for collaboration in writing and writing feedback.Journal of Second Language Writing, 21(4), 364-374. Retrieved from http://dx.doi.org/10.1016/j.jslw.2012.09.005

Zammit, K. P. (2011). Connecting multiliteracies and engagement of students from low socio-economic backgrounds: Using Bernstein's pedagogic discourse as a bridge. Language and Education, 25(3), 203-220. 
Zhang, G. (2010). Technology uses in creating second language learning environments: When learners are creators (Doctoral dissertation). Available from ProQuest Dissertations \& Theses database (AAT No. 3417670).

\section{Eva Sujee}

Council for Quality Assurance in General and Further Education and Training, South Africa 